\title{
Multi-Electric Field Modulation for Photocatalytic Oxygen Evolution: Enhanced Charge Separation by Coupling Oxygen Vacancies with Faceted Heterostructures
}

Tingcha Wei ${ }^{\mathrm{a}, \mathrm{b}}$, Yanan Zhu ${ }^{\mathrm{b}}$, Zhenao Gu${ }^{\mathrm{d}}$, Xiaoqiang An ${ }^{\mathrm{a}, \mathrm{c},}$, Li-min Liu ${ }^{\mathrm{b}, *}$, Yuxuan Wu ${ }^{\mathrm{b}}$, Huijuan Liu ${ }^{\mathrm{a}, \mathrm{c}}$, Junwang Tang ${ }^{\mathrm{e}, *}$ and Jiuhui $\mathrm{Qu}^{\mathrm{a}, \mathrm{d}}$

${ }^{\text {a }}$ Center for Water and Ecology, Tsinghua University, Beijing 100084, China

E-mail: xqan@mail.tsinghua.edu.cn

${ }^{\mathrm{b}}$ Beijing Computational Science Research Center, Beijing 100193, China.

E-mail: limin.liu@csrc.ac.cn

c School of Environment, State Key Joint Laboratory of Environment Simulation and Pollution Control, Tsinghua University, Beijing 100084, China

${ }^{\mathrm{d}}$ University of Chinese Academy of Sciences, Beijing 100049, China.

${ }^{c}$ Department of Chemical Engineering, University College London, Torrington Place, London, WC1E 7JE, UK.

E-mail: junwang.tang@ucl.ac.uk

Abstract: A fundamental challenge of photocatalysis is developing efficient strategies to suppress the recombination of photogenerated charge carriers. Herein, $\mathrm{ZnO} / \mathrm{BiVO}_{4}$ hierarchical nanostructures were exemplified to demonstrate new concept of multi-electric field-assisted charge separation. The contribution of both facet engineering and defect modulation to the facilitated photocatalysis was confirmed by both experimental observations and theoretical calculations. Such integration of built-in fields in faceted $\mathrm{BiVO}_{4}$ and anisotropic $\mathrm{ZnO}$ nanorods, together with the possible $\mathrm{Z}$-scheme at the interfaces resulted into $1.36 \mathrm{mmol} \bullet \mathrm{h}^{-1} \cdot \mathrm{g}^{-1} \mathrm{O}_{2}$ produced under visible light irradiation, and more than one order of magnitude enhanced apparent quantum yield at $450 \mathrm{~nm}$. This work not only provides fundamental insights into the facet-dependent distribution of interfacial defects, but also offers a strategy for the design of faceted heterojunctions with controlled vacancies for significantly enhanced charge separation.

Keyword: Photocatalysis, hierarchical structures, oxygen vacancies, water splitting, DFT calculations.

\section{Introduction}

By far, the industrial application of photocatalysis is heavily limited by the very moderate efficiency mainly caused by the fast recombination of photoinduced charge carriers [1,2]. Great efforts have been devoted to improve the charge separation in semiconductors, while constructing internal electric field has been considered as a promising way [3,4]. Due to the spontaneous spatial separation of 
photoinduced electrons and holes, crystal facet engineering can provide intrinsic driving force for charge separation, and significantly impact on the surface adsorption or reactive radical formation, which is a prerequisite for high-efficiency photocatalysis [5,6]. Among these developed faceted semiconductors, decahedron shaped $\mathrm{BiVO}_{4}$ has stood out as one of the most attractive candidates for water oxidation $[7,8]$. Although with such success of controlled facets, performance of faceted $\mathrm{BiVO}_{4}$ is still unsatisfactory due to the existing charge recombination in both bulk and surface.

Besides the strategy of faceted photocatalysts which can form internal electric field and suppress charge recombination in crystal bulk, the other strategy of a heterostructure, in particular a Z-scheme, has also been proved successful in separation of charge carriers for surface reactions $[9,10]$. The interfacial potential difference of a Z-scheme which dominates the electric field due to the heterojunction substantially relies on the contact between facets of different semiconductors $[11,12]$. The complexity of hybrid structures inevitably causes the difficulty in simultaneously tailoring the crystal orientations of different components in a heterojunction. By far, the assembly of 3-D heterostructured nanoarchitectures with crystallographically ordered alignment between building blocks is still a grand challenge $[13,14]$, however this can integrate the above mentioned two strategies together to efficiently overcome the charge recombination in the bulk and surface of a photocatalyst. Due to the difficulty in building faceted heterostructures with definite interfacial contact, the fundamental understanding of crystal facet orientation and charge separation in multiple-component structures remains largely unknown. Therefore to integrate facet-induced electric field with Z-scheme-induced electric field can not only provide an ideal way to investigate the charge transfer in the facet-dependent multi-component architectures, but also produce novel strategy for the design of high-efficiency photocatalysts [15].

In general, electron-hole separation and surface reaction are two dominant steps for high-efficiency photocatalysis apart from visible light absorption. From the viewpoint of charge transfer kinetics, it is imperative to consider the influence of interfacial electronic structure on charge separation. Foremost among these interfacial factors involved is oxygen vacancy, which can conceivably behave as adsorption and active sites for catalytic reactions. In fact, exploration of emergent behavior through oxygen vacancy modulation has already triggered an explosion of research interests [16-19]. Our recent study also evidenced the significant impact of spatial distribution of oxygen vacancies on the activity of a photocatalyst [20,21]. Nevertheless, the relationship between facet exposure and oxygen vacancies is still an open question. In this regard, it is a critical point to achieve an in-depth understanding on the charge separation behavior through combining the strategies of facet engineering and oxygen vacancy modulation [22].

Taking these factors into consideration, a multi-electric field strategy was proposed to facilitate 
charge separation in this study, which has been achieved by assembling oriented $\mathrm{ZnO}$ nanorods with modulated oxygen vacancies on faceted $\mathrm{BiVO}_{4}$. The significant impact of crystal facets on the formation and spatial distribution of interfacial oxygen vacancies was systematically investigated by both experimental observations and theoretical calculations. $\mathrm{ZnO} / \mathrm{BiVO}_{4}$ heterostructures with tailored facet orientation (i.e. forming double built-in electric fields) and modulated oxygen vacancies (i.e. may generating a Z-scheme potential) exhibited one-order-of magnitude enhanced activity for visible-light-driven water oxidation, corresponding to a high quantum yield of $5.0 \%$ at $450 \mathrm{~nm}$.

\section{Experimental section}

\subsection{Synthesis of $\mathrm{BiVO}_{4}$}

$\mathrm{BiVO}_{4}$ samples were synthesized by a hydrothermal method. Typically, $\mathrm{NH}_{4} \mathrm{VO}_{3}(15 \mathrm{mM})$ and $\mathrm{Bi}\left(\mathrm{NO}_{3}\right)_{3} \cdot 5 \mathrm{H}_{2} \mathrm{O}(15 \mathrm{mM})$ were dissolved in $30 \mathrm{~mL}$ of $2.0 \mathrm{M}$ nitric acid solution. The $\mathrm{pH}$ value of solution was adjusted to 2.0 with ammonia solution under stirring until the formation of orange precipitates. After aging for about $0.5 \mathrm{~h}$, the precipitates at the bottom of beaker were transferred into a Teflon-lined stainless steel autoclave with a capacity of $50 \mathrm{~mL}$ and hydrothermally treated at $200{ }^{\circ} \mathrm{C}$ for $24 \mathrm{~h}$. When the autoclave was cooled to room temperature, vivid yellow powders were collected by centrifugation, washed with de-ionized water and dried at $60{ }^{\circ} \mathrm{C}$ overnight. For comparison, $\mathrm{BiVO}_{4}$ nanosheets were also fabricated by normal pressure hydrothermal reactions carried out at $165{ }^{\circ} \mathrm{C}$ for 12 h.

\subsection{Assembly of $\mathrm{ZnO}$ nanorod arrays onto faceted $\mathrm{BiVO}_{4}$}

To preset $\mathrm{ZnO}$ seeds on the surface of $\mathrm{BiVO}_{4}$ crystals, $0.5 \mathrm{~g}$ of $\mathrm{BiVO}_{4}$ was dispersed in $30 \mathrm{ml}$ absolute ethanol with $3.6 \mathrm{mM}$ zinc acetate $\left(\mathrm{Zn}\left(\mathrm{CH}_{3} \mathrm{CO}_{2}\right)_{2}\right)$. After stirred for $0.5 \mathrm{~h}$, the solution was dried and then annealed at $400{ }^{\circ} \mathrm{C}$ for $1 \mathrm{~h}$. A hydrothermal reaction was carried out to grow $\mathrm{ZnO}$ nanorods on $\mathrm{BiVO}_{4}$. The reaction solution was prepared by dissolving zinc nitrate $\left(\mathrm{Zn}\left(\mathrm{NO}_{3}\right)_{2} \bullet 6 \mathrm{H}_{2} \mathrm{O}, 5 \mathrm{mM}\right)$, hexamethylenetetramine (HMTA, $\left.\left(\mathrm{CH}_{2}\right)_{6} \mathrm{~N}_{4}, 5 \mathrm{mM}\right)$ and ammonia hydroxide $\left(\mathrm{NH}_{3} \mathrm{OH}, 28 \mathrm{wt} \%, 0.24 \mathrm{M}\right)$ in $30 \mathrm{ml}$ of distilled water. Typically, $\mathrm{BiVO}_{4}$ crystals with $\mathrm{ZnO}$ seeds were added into the reaction solution under magnetic stirring and then treated at $80{ }^{\circ} \mathrm{C}$ for $1 \mathrm{~h}$ in Teflon-lined stainless steel autoclave. $\mathrm{ZnO} / \mathrm{BiVO}_{4}$ heterostructures were obtained by annealing the products in air at $400{ }^{\circ} \mathrm{C}$ for 2 h. $\mathrm{V}_{\mathrm{o}}-\mathrm{ZnO} / \mathrm{BiVO}_{4}$ heterostructures with abundant oxygen vacancies were obtained by treating the products at $200{ }^{\circ} \mathrm{C}$ for $0.5 \mathrm{~h}$ in vacuum drying oven. To demonstrate the significant impact of interfacial defects on the photoactivity, electronic structure of $\mathrm{ZnO} / \mathrm{BiVO}_{4}$ heterostructures was modulated through controlling the atmospheric conditions of calcination. A facile vacuum treatment method was used to fabricate heterostructures with different concentration of oxygen vacancies. Unless otherwise specified, sample fabricated by vacuum-treating for 1 hour is denoted as $\mathrm{V}_{\mathrm{o}}-\mathrm{ZnO} / \mathrm{BiVO}_{4}$. A 
two-hour treatment was also used to fabricate $2 \mathrm{~h}-\mathrm{V}_{\mathrm{o}}-\mathrm{ZnO} / \mathrm{BiVO}_{4}$ with higher concentration of oxygen vacancies. Differently, those as-formed oxygen vacancies could be eliminated by air calcinations for several hours. The corresponding sample is denoted as treated $\mathrm{V}_{\mathrm{o}}-\mathrm{ZnO} / \mathrm{BiVO}_{4}$.

\subsection{Materials characterization}

The morphology of the products was characterized by field emission scanning electron microscope (FE-SEM, SIGMA) and high-resolution transmission electron microscope (HR-TEM, JEOL-2010). Elemental analysis was performed with energy dispersive spectrometer (EDS, EDAX Inc.) attached to the microscopes. X-ray diffraction (XRD) was performed using X'Pert PRO MPD. The surface elemental composition and the VBM were analyzed by X-ray photoelectron spectroscopy (XPS) and ultraviolet photoelectron spectroscopy (UPS, ESCALAB 250Xi). Diffuse reflectance and absorption spectra were collected by UV-vis-NIR spectrophotometer (Cary 5000). Electron spin resonance (ESR) analysis was carried out using a Bruker E500 spectrometer. During the data acquisition, the tube temperature was maintained at $77 \mathrm{~K}$ by liquid nitrogen.

\subsection{Photocatalytic $\mathrm{O}_{2}$ evolution}

Photocatalytic $\mathrm{O}_{2}$ evolution was executed in an enclosed top-irradiation cell with a Pyrex window. The light source was a 300W Xe lamp (CEL-HXF300) equipped with a $420 \mathrm{~nm}$ cut-off filter. Typically, 50 mg of sample was suspended in $100 \mathrm{~mL}$ of $0.05 \mathrm{M} \mathrm{AgNO}_{3}$ solution. Before irradiation, the reaction system was thoroughly degassed by evacuation in order to drive off the air inside. The amount of $\mathrm{O}_{2}$ generated was quantified by gas chromatography with thermal conductivity detection (TCD) instrument (SP-6890, Shanghai Techcomp, nitrogen as a carrier gas).

\subsection{Photoelectrochemical measurements}

The electrodes were prepared by a drop-casting method. Certain amount of samples were dropped onto FTO substrates $\left(1 \times 1.5 \mathrm{~cm}^{2}\right)$, dried in air and calcined at $573 \mathrm{~K}$ for $2 \mathrm{~h} . \mathrm{V}_{\mathrm{o}}-\mathrm{ZnO} / \mathrm{BiVO}_{4}$ were achieved by heating as-prepared electrodes in vacuum drying oven at $200{ }^{\circ} \mathrm{C}$ for $0.5 \mathrm{~h}$.

Potentiostatic electrical impedance spectroscopic (EIS) measurements were carried out using a three-electrode setup, where $\mathrm{Pt}$ wire and $\mathrm{Ag} / \mathrm{AgCl}$ electrode were used as the counter and reference electrodes, respectively. Electrolyte was $0.5 \mathrm{M} \mathrm{Na}_{2} \mathrm{SO}_{4}(\mathrm{pH}=6.8)$ solution. EIS spectra were recorded under an $\mathrm{AC}$ perturbation signal of $5 \mathrm{mV}$ over the frequency range from $1 \mathrm{MHz}$ to $100 \mathrm{mHz}$. The Mott-Schottky curces were measured at the frequency of $2000 \mathrm{~Hz}$.

\subsection{Kelvin Probe Force Microscopy measurements}

The surface photovoltage setup was installed in a Kelvin Probe Force Microscopy (KPFM) setup consisting of a modified Dimension Icon and operated in lift mode under $\mathrm{N}_{2}$ protection [23]. To acquire the surface photovoltaic spectra, the light of a $500 \mathrm{~W}$ xenon-arc lamp was focused through the entrance slit of a Zolix Omni- $\lambda 500$ monochromator onto the diffraction grid. The outgoing monochromatic light 
was focused on the entrance of a $100 \mu \mathrm{m}$ optical silica fiber by a $30 \mathrm{~mm}$ UV-Grade Fused Silica lens coupled with a Thorlabs LMU-40X-NUV objective lens. The end of the fiber was mounted in a fixed position close to the sample with a low grazing angle of 20 to ensure that the sample under the measuring AFM tip was properly illuminated. To quantify the transient SPV signals, the varied surface potential signals were fed to a Stanford SR 830 lock-in amplifier and synchronized with the chopped signals.

\subsection{Fluorescence lifetime imaging measurements}

Photoluminescence images and decay profiles of $\mathrm{ZnO}$ nanorods were recorded using a fluorescence lifetime imaging microscopy (FLIM) objective-scanning confocal microscope system. Samples were analysis by Q2 laser scanning nanoscope (ISS Inc.), contain Laser MaiTai spectra-physics for two-photon excitation and Olympus BX51WI microscope for monitor the fluorescence emission.

\subsection{First-principle simulations}

DFT calculations were performed using the Vienna Ab Initio Simulation Package (VASP) code [24-26]. The electron-ion interaction was described by the projector augmented wave (PAW) method [27,28]. Moreover, the electron wave functions were expanded by a plane wave cutoff of $500 \mathrm{eV}$. Hubbard U correction with the corresponding $\mathrm{U}$ values being set to 2.7 and $12 \mathrm{eV}$ were applied on the $3 \mathrm{~d}$ orbitals of $\mathrm{V}$ and $3 \mathrm{~d}$ orbitals of $\mathrm{Zn}$, respectively [29]. For the structure optimization and total energy calculations, $(1 \times 1 \times 1)$ K-point was adopted (Fig. 1). Besides, $(3 \times 3 \times 1)$ K-point was used to calculate the DOS of the structure. The vacuum separation space between slabs was $20 \AA$. In order to simulate the defect structure, an oxygen atom was removed from the structure to model the $\mathrm{V}_{\mathrm{o}}$ defective heterostructures. We calculated structure with different $V_{0}$ sites to find the most stable one to check the DOS. The valence band edge of the pristine $\mathrm{ZnO}$ was mostly composed of $\mathrm{O} 2 \mathrm{p}$ states, and the conduction band edge was mainly of $\mathrm{Zn} 3 \mathrm{~d}$ states. The VBM and CBM of the pristine $\mathrm{BiVO}_{4}$ were mainly composed of $\mathrm{O} 2 \mathrm{p}$ and V $3 \mathrm{~d}$ states, respectively. 


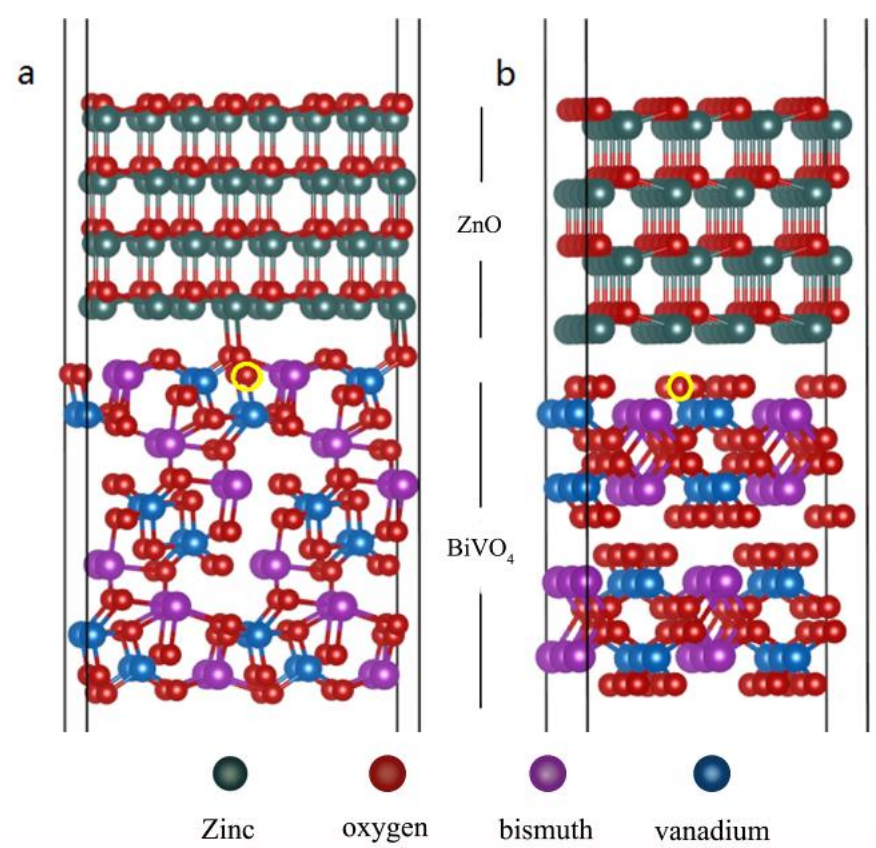

Fig. 1. Schematic representation of atomic structures of $\mathrm{ZnO} / 110-\mathrm{BiVO}_{4}$ heterostructures (a) and $\mathrm{ZnO} / 010-\mathrm{BiVO}_{4}$ heterostructures (b). The atoms with yellow circles stand for the oxygen vacancy sites.

\section{Results and discussion}

Faceted photocatalysts are essential prerequisite for realizing the strategy of multi-electric field modulation. $\mathrm{BiVO}_{4}$ decahedrons were selected as substrates for the heteroepitaxial growth of another faceted semiconductor. The light-induced formation of built-in electric field in $\mathrm{BiVO}_{4}$ was firstly studied by the KPFM measurements. The intense surface voltage signal on the side facets indicates that the photoinduced holes are transferred from the bulk to the surface (Fig. S1) [23,30]. This process is thermodynamically spontaneous, as our first-principles calculations confirm the negatively shifted energy bands of $\{110\}$ facets, compared to that of $\{010\}$ facets. Because of the polar-induced anisotropic transport of electrons and holes toward the tops and lateral surfaces, 1-D ZnO nanorods were selected to enhance the charge separation in the hierarchical nanostructures [31]. For wurtzite $\mathrm{ZnO}$, the alternate stacking of positively charged cations and negatively charged anions along the c axis results in the internal electric field, leading to the accumulation of photogenerated electrons on the polar facets and holes on the unpolar facets [32,33]. This hypothesis can be well proved by the zone-specific fluorescence intensity and photoluminescence lifetime in the temporally resolved photoluminescence (TRPL) measurements. Fig. S2 clearly shows the spatial variations in PL intensity and charge carrier lifetimes in individual $\mathrm{ZnO}$ nanorod. Compared to the lateral side of nanorod, both ends exhibit much stronger light emission, indicating the preferential migration of electrons to the polar $\{001\}$ facets [34]. The obvious PL quenching indicates that the serious recombination of charge carriers in pristine $\mathrm{ZnO}$ could be effectively inhibited through heterostructure design $[35,36]$.

The spontaneous charge separation in faceted photocatalysts can be evidenced by the selective 
photodeposition of metal/metal oxide. $\mathrm{AgNO}_{3}$ and $\mathrm{Co}\left(\mathrm{NO}_{3}\right)_{2}$, which could be photoreduced or photooxidized into $\mathrm{Ag}$ and $\mathrm{Co}_{3} \mathrm{O}_{4}$, were used as precursors to determine the distribution of photogenerated charge carriers [7]. For $\mathrm{BiVO}_{4}$ decahedrons, Ag nanoparticles with an average size of 55 $\mathrm{nm}$ are mainly deposited on the $\{010\}$ facets (Fig. 2a), while irregular $\mathrm{Co}_{3} \mathrm{O}_{4}$ particles are on the $\{110\}$ facets (Fig. 2b). It indicates the distribution of electrons and holes on different facets of $\mathrm{BiVO}_{4}$ upon light irradiation, which is inconsistent with the KPFM measurements. Based on the photodeposition of $\mathrm{Ag}$, it can be deduced that the end-accumulation of electrons results in the formation of irregular $\mathrm{Ag}$ nanoarchitectures on the tips of $\mathrm{ZnO}$ nanorods (Fig. 2c). In contrast, the selective growth of $\mathrm{Co}_{3} \mathrm{O}_{4}$ nanoparticles on the lateral $\{010\}$ facets evidences the different spatial distribution of charge carriers (Fig. 2d).

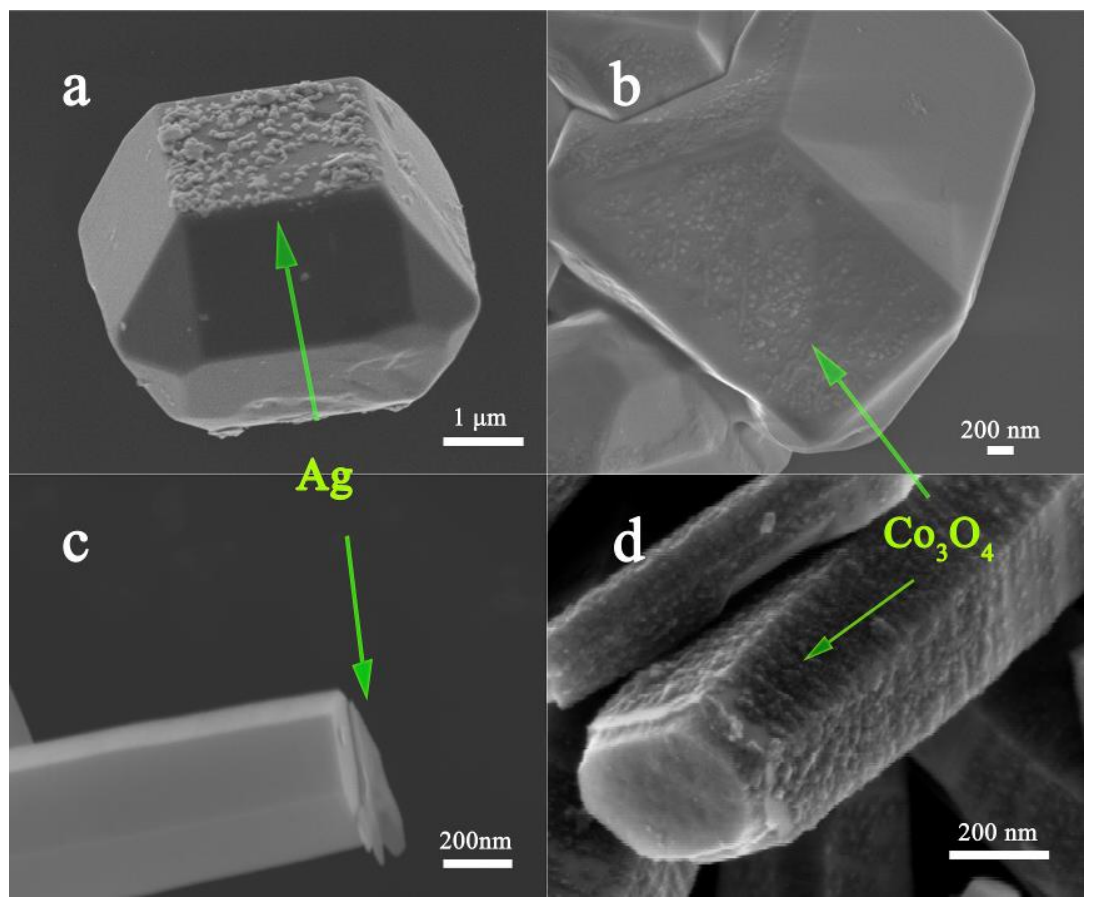

Fig. 2. SEM images of (a) $\mathrm{Ag}-\mathrm{BiVO}_{4}$, (b) $\mathrm{Co}_{3} \mathrm{O}_{4}-\mathrm{BiVO}_{4}$, (c) $\mathrm{Ag}-\mathrm{ZnO}$ nanorods and (d) $\mathrm{Co}_{3} \mathrm{O}_{4}-\mathrm{ZnO}$ nanorods.

In parallel, a seeded growth approach was used for the oriented growth of $\mathrm{ZnO}$ photocatalyst on $\mathrm{BiVO}_{4}$ (step i-iii in Fig. 3a). In the last (step iv in Fig. 3a), electronic structure of 3-D nanoarchitectures was modulated through controlling the atmospheric condition of calcination, resulting into interfacial oxygen vacancy-rich nanoarchitectures (denoted $\mathrm{V}_{\mathrm{o}}-\mathrm{ZnO} / \mathrm{BiVO}_{4}$ ). As confirmed by XRD (Fig. S3) and morphology observations (Fig. 3b-d and Fig. S4), well-aligned nanorod arrays were successfully assembled onto the top $\{010\}$ surfaces and isosceles tapezoidal $\{110\}$ sides of $\mathrm{BiVO}_{4}$ decahedrons, through controlling the [001] oriented growth of $\mathrm{ZnO}$ (Fig. S5). 


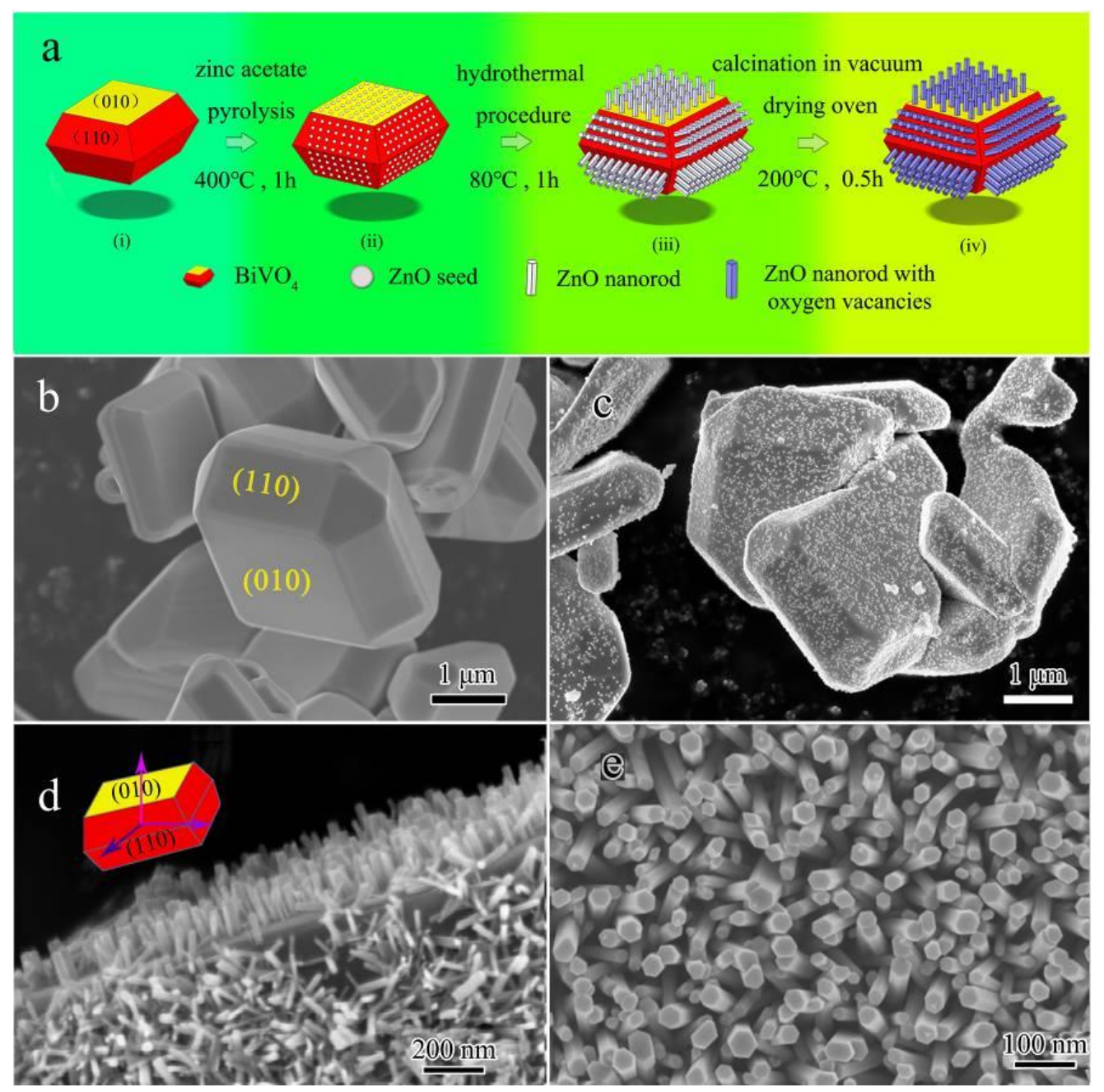

Fig. 3. (a) Schematic illustration of the fabrication of $\mathrm{ZnO} / \mathrm{BiVO}_{4}$ with modulated interfacial structures; (b-e) SEM images of corresponding samples in a (i-iv).

The band positions of $\mathrm{BiVO}_{4}$ and $\mathrm{ZnO}$ were next observed. According to the Mott-Schottky plots (Fig. 4a), the flat band potential $\left(\mathrm{V}_{\mathrm{fb}}\right)$ of $\mathrm{BiVO}_{4}$ and $\mathrm{ZnO}$ are located at 0.17 and $-0.8 \mathrm{~V}$ vs. $\mathrm{Ag} / \mathrm{AgCl}$. The relatively positive $\mathrm{V}_{\mathrm{fb}}$ of $\mathrm{BiVO}_{4}$ is in consistent with that reported in the literatures [37]. Ultraviolet photoelectron (Fig. 4b) and diffuse reflectance spectra (Fig. S6) confirm the relatively more negative valence band maximum (VBM) and conduction band minimum (CBM) of $\mathrm{ZnO}$ than that of $\mathrm{BiVO}_{4}$, also in good agreement with $\mathrm{V}_{\mathrm{fb}}$ measured above and that measured by VB XPS (Fig. S7). All these confirm the formation of Type II heterojunction, while a comprehensive understanding of the charge transfer behavior is highly desirable to reveal the effects of facet engineering and interfacial defects on the efficiency of $\mathrm{ZnO} / \mathrm{BiVO}_{4}$.

The chemical states of elements in the junction were studied by XPS. According to the Zn $2 p$ spectra of $\mathrm{ZnO} / \mathrm{BiVO}_{4}$ (Fig. S8a), the slightly rightward shift of $\mathrm{Zn} 2 \mathrm{p}_{1 / 2}$ and $\mathrm{Zn} 2 \mathrm{p}_{3 / 2}$ to higher binding energies by $1.0 \mathrm{eV}$ is consistent with oxygen vacancy-rich $\mathrm{ZnO}$ [38]. Furthermore, the $\mathrm{V} 2 \mathrm{p}_{3 / 2}$ and $\mathrm{V} 2 \mathrm{p}_{1 / 2}$ peaks of $\mathrm{BiVO}_{4}$ are symmetric and located at 516.5 and $524.2 \mathrm{eV}$, respectively. In contrast, asymmetric peaks 
are observed in $\mathrm{ZnO} / \mathrm{BiVO}_{4}$. After convolution using Gaussian distribution, the signals at 516.1 and $523.6 \mathrm{eV}$ evidences the formation of $\mathrm{V}^{4+}$ caused by oxygen vacancies (Fig. 4c) [39]. Thus, interfacial coupling between $\mathrm{ZnO}$ and $\mathrm{BiVO}_{4}$ is favorable for the formation of nonstoichiometric structures (Fig. S8b and Fig. S9a). The spontaneous formation of defective interfaces is consistent with our recent research [20].

The interfacial electronic structure of hetrojunction was further studied by ESR. Compared to $\mathrm{BiVO}_{4}$, the junction exhibits a strong peak centered at $\mathrm{g}=1.960$ and another weak one at $\mathrm{g}=2.003$. The former one can be ascribed to oxygen vacancies in the crystal lattice of $\mathrm{ZnO}$, while the latter one is the characteristic peak of surface oxygen vacancies (Fig. S9b) [40]. It indicates that oxygen-deficient nanostructures are easily formed when assembling $\mathrm{ZnO}$ nanorods onto faceted $\mathrm{BiVO}_{4}$ (Fig. S9b). When vacuum heating was used, the significantly increased ESR peak at $\mathrm{g}=2.003$ indicates the generation of sufficient surface defects in $\mathrm{V}_{\mathrm{o}}-\mathrm{ZnO} / \mathrm{BiVO}_{4}$ (Fig. 4d). It is believed that oxygen vacancy modulation can provide a new platform towards developing more efficient heterostructured photocatalysts.
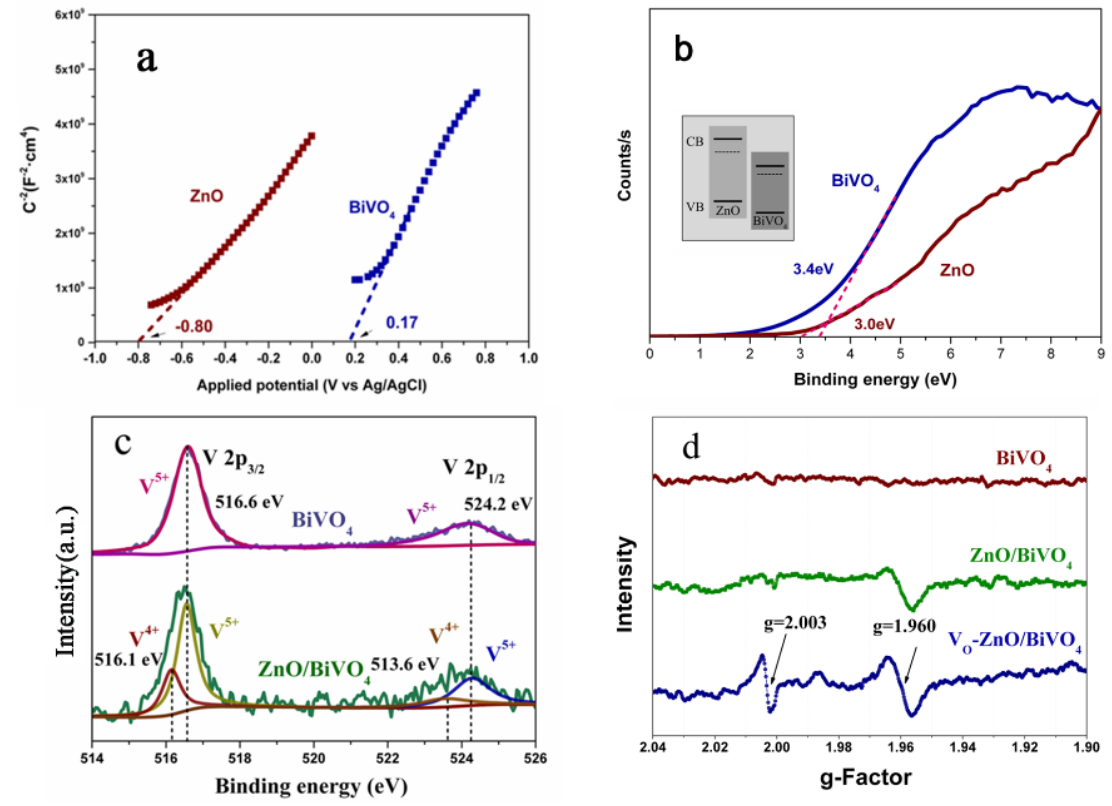

Fig. 4. (a) Mott-Schottky plots of $\mathrm{BiVO}_{4}$ and $\mathrm{ZnO}$; (b) Ultraviolet photoelectron spectra of $\mathrm{BiVO}_{4}$ and $\mathrm{ZnO}$. Inset of $\mathrm{b}$ shows their energy band alignment; (c) XPS V 2p spectra of $\mathrm{BiVO}_{4}$ and $\mathrm{ZnO} / \mathrm{BiVO}_{4}$; (d) ESR spectra of $\mathrm{BiVO}_{4}, \mathrm{ZnO} / \mathrm{BiVO}_{4}$ and $\mathrm{V}_{\mathrm{o}}-\mathrm{ZnO} / \mathrm{BiVO}_{4}$.

First-principle calculations were carried out to investigate the electronic structure of faceted multi-component architectures. According to the calculated density of states (DOS) for the interfaces between $\{001\}-\mathrm{ZnO},\{010\}-$ and $\{110\}-\mathrm{BiVO}_{4}$, the introduction of oxygen vacancy inevitably generates defected states mainly composed of V 3d states (Fig. S10). This agrees well with the appearance of $\mathrm{V}^{4+}$ in the XPS spectra. To reveal the influence of facet selection on the formation of oxygen vacancies, their possible formation sites in different faceted heterostructures were evaluated by 
calculating formation energy. When $\{001\}$ facets of $\mathrm{ZnO}$ (bottom of the nanorods) are coupled with $\{110\}$ facets of $\mathrm{BiVO}_{4}$ (Table 1), interface of $\mathrm{ZnO}$ is prone to forming oxygen vacancy (Fig. 5). The calculated formation energy of oxygen vacancy on $\{110\}$ facets of $\mathrm{BiVO}_{4}$ is slightly lower than $\mathrm{ZnO}$, while the most possible sites are at sub-interface. However, when $\{001\}$ facets of $\mathrm{ZnO}$ contact with $\{010\}$ facets of $\mathrm{BiVO}_{4}$, sub-interface of $\mathrm{ZnO}$ and interface of $\mathrm{BiVO}_{4}$ seems to be the most stable sites for relatively low defect formation (Table 2). In other words, the interfacial oxygen vacancies are more likely formed in the $\mathrm{ZnO}$ top layer when $\mathrm{ZnO}$ nanorods grow on the $\{110\}$ facets of $\mathrm{BiVO}_{4}$, while they are in the top layer of $\mathrm{BiVO}_{4}$ when $\mathrm{ZnO}$ nanorods grow on the $\{010\}$ facets of $\mathrm{BiVO}_{4}$. This phenomenon well demonstrates the facet-dependant distribution of interfacial oxygen vacancies in the heterostructures, consistent with our recent report [21].

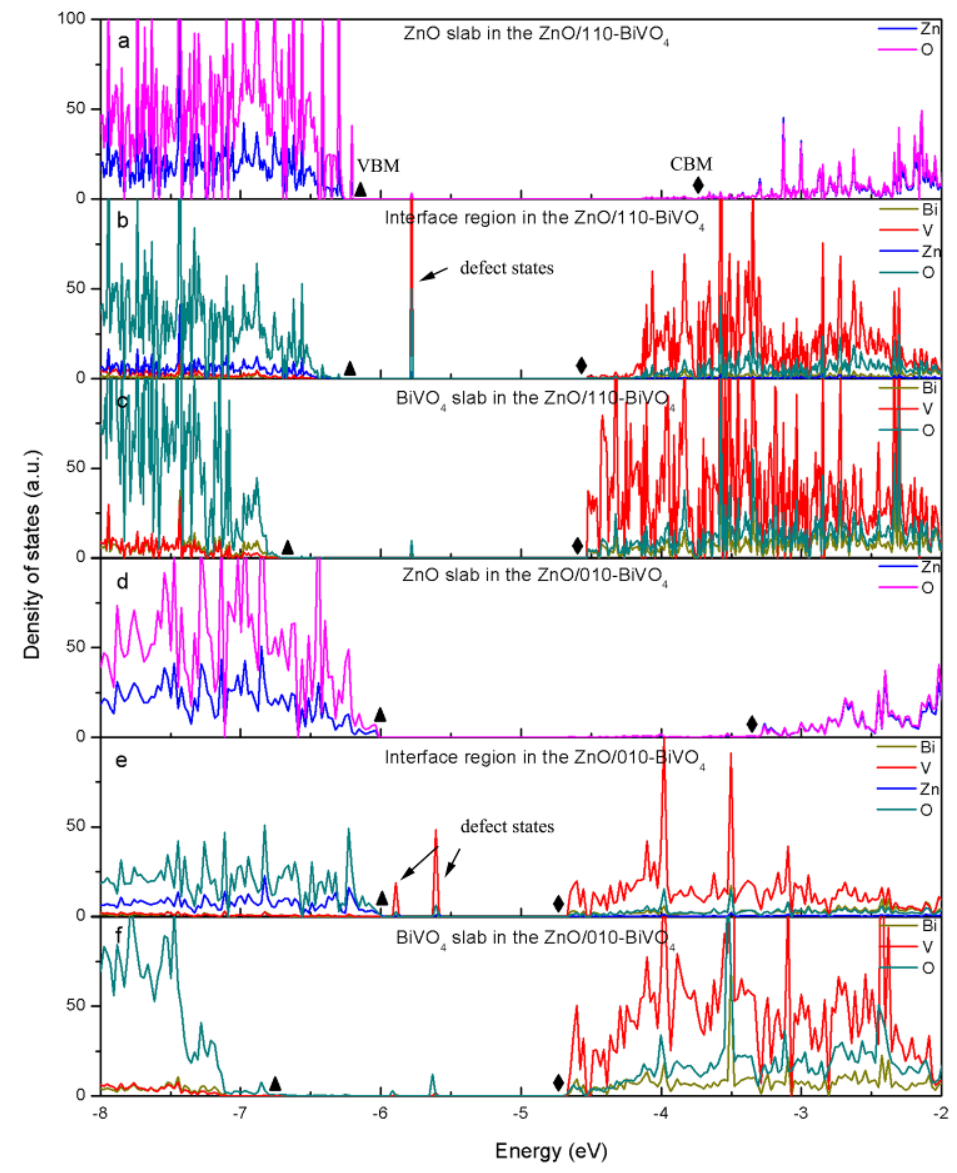

Fig. 5. Density of state plots for $\mathrm{ZnO} / 110-\mathrm{BiVO}_{4}(\mathrm{a}-\mathrm{c})$ and $\mathrm{ZnO} / 010-\mathrm{BiVO}_{4}$ (d-f) with oxygen vacancies. Here, (a), (b) and (c) exhibits the PDOSs of $\mathrm{ZnO}$, interfacial region and $\mathrm{BiVO}_{4}$ sides for $\mathrm{ZnO} / 110-\mathrm{BiVO}_{4}$, respectively. (d), (e) and (f) show the corresponding PDOSs of $\mathrm{ZnO}$, interfacial region, and $\mathrm{BiVO}_{4}$ sides for $\mathrm{ZnO} / 010-\mathrm{BiVO}_{4}$, respectively. The triangle represents the highest occupied states for each region, while the rhombus indicates the lowest unoccupied states.

Table 1. Calculated formation energy of oxygen vacancy on different sites in $\mathrm{ZnO} / 110-\mathrm{BiVO}_{4}$ 
heterostructures (in $\mathrm{eV}$ ).

\begin{tabular}{|c|c|c|c|c|c|c|c|}
\hline \multirow{2}{*}{$\mathrm{ZnO} / 110-\mathrm{BiVO}_{4}$} & \multicolumn{2}{|c|}{$\begin{array}{c}\mathrm{ZnO} \\
\text { sub-interface }\end{array}$} & \multicolumn{3}{|c|}{$\begin{array}{c}\text { interfac } \\
\mathrm{e}\end{array}$} & \multicolumn{2}{|c|}{$\begin{array}{c}\mathrm{BiVO}_{4} \\
\text { sub-interface }\end{array}$} \\
\hline & $V_{0-1}{ }^{a)}$ & $V_{0}-2$ & $\mathrm{~V}_{\mathrm{O}-3}$ & $\mathrm{~V}_{\mathrm{O}-4}$ & $V_{0}-5$ & $\mathrm{~V}_{0}-6$ & $\mathrm{~V}_{\mathrm{O}-7}$ \\
\hline Formation energy & 5.22 & 5.06 & 3.14 & 3.92 & 3.04 & 2.75 & 3.79 \\
\hline
\end{tabular}

a) The possible formation sites of oxygen vacancy as shown in Fig. S11.

Table 2. Calculated formation energy of oxygen vacancy on different sites in $\mathrm{ZnO} / 010-\mathrm{BiVO}_{4}$ heterostructures (in eV).

\begin{tabular}{|c|c|c|c|c|c|c|c|}
\hline \multirow{2}{*}{$\mathrm{ZnO} / 010-\mathrm{BiVO}_{4}$} & \multicolumn{2}{|c|}{$\begin{array}{c}\mathrm{ZnO} \\
\text { sub-interface }\end{array}$} & \multicolumn{3}{|c|}{ interface } & \multicolumn{2}{|c|}{$\begin{array}{c}\mathrm{BiVO}_{4} \\
\text { sub-interface }\end{array}$} \\
\hline & $V_{0}-1$ & $V_{0}-2$ & $V_{0}-3$ & $V_{0}-4$ & $\begin{array}{c}\text { Vo- } \\
5\end{array}$ & $V_{0}-6$ & $V_{0}-7$ \\
\hline Formation energy & 3.22 & 2.11 & 4.96 & 3.68 & 2.49 & 3.66 & 3.39 \\
\hline
\end{tabular}

With specifically modulated crystal facets and defective structures, the activity of the $\mathrm{ZnO} / \mathrm{BiVO}_{4}$ heterostructures for water photooxidation was thereafter evaluated. Under visible light irradiation (Fig. $6 a)$, the activity of heterostructured photocatalysts is highly dependent with the concentration of oxygen vacancies (Fig. S12a). $\mathrm{V}_{\mathrm{o}}-\mathrm{ZnO} / \mathrm{BiVO}_{4}$ presents highest oxygen evolution rate of $68 \mu \mathrm{mol} \bullet \mathrm{h}^{-1}$, which is nearly 4 times higher than the $\mathrm{ZnO} / \mathrm{BiVO}_{4}$ and one-order-magnitude higher than pristine $\mathrm{BiVO}_{4}$. $\mathrm{The}$ concentration of oxygen vacancies can be controlled by experimental conditions (as described in supporting information). According to Table S1, the sample also exhibits superior photocatalytic performance than other $\mathrm{BiVO}_{4}$-based photocatalysts reported before. The optimized $\mathrm{V}_{\mathrm{o}}-\mathrm{ZnO} / \mathrm{BiVO} 4$ shows an apparent quantum yield (AQY) of $5.0 \%$ at $450 \mathrm{~nm}$ (Fig. 6b), which is 10 times higher than $\mathrm{BiVO}_{4}(0.5 \%)$. By comparing AQY values of $\mathrm{BiVO}_{4}$ and $\mathrm{ZnO} / \mathrm{BiVO}_{4}$, the positive contribution of spontaneously formed interfacial defects to the superior visible light photoactivity can be confirmed (Fig. S12b). Three consecutive cycling tests indicate the considerable stability of the defective facet-engineered photocatalysts (Fig. S13). Apart from the water oxidation mentioned above, the activity of faceted heterostructures for the photodegradation of organic pollutants was further evaluated (Fig. S14). The 6-fold improved performance of $\mathrm{V}_{\mathrm{o}}-\mathrm{ZnO} / \mathrm{BiVO}_{4}$ indicates the significant contribution of multi-electric field to the superior photoactivity.

To prove the enhanced charge transfer and separation dominated by the multi-electric fields, both TRPL and surface photovoltage spectroscopies were monitored (Fig. S15). These spectroscopies show a 3-fold increased lifetime of charge carriers and 5-fold enhanced photovoltage response in 
$\mathrm{V}_{\mathrm{o}}-\mathrm{ZnO} / \mathrm{BiVO}_{4}$ compared with the reference $\mathrm{BiVO}_{4}$, experimentally proving the efficient charge separation by this faceted heterojunction (Table S2). Based on the modeling results, bandgap measurement and other spectroscopy results, an underlying mechanism of facet engineered photocatalysts for water oxidation was proposed in Fig. 6c. Compared to $\mathrm{BiVO}_{4}, \mathrm{ZnO}$ possesses more negative $\mathrm{CB}$ and $\mathrm{VB}$ positions. Upon visible light irradiation, electrons in the $\mathrm{VB}$ of $\mathrm{BiVO}_{4}$ could be excited to the CB level, while only defect excitation could be achieved for ZnO. According to the density function theory (DFT) simulation and experimental validation, energy band offset between $\{010\}$ and $\{110\}$ facets generated internal electric field in faceted $\mathrm{BiVO}_{4}$. This spontaneous field potentials provide preliminary driving force for the transfer and separation of charge carriers from bulk to different surfaces after excitation, with electrons accumulated on the $\{010\}$ facets and holes on the $\{110\}$ facets in faceted $\mathrm{BiVO}_{4}$. When $\mathrm{ZnO}$ nanorods were perpendicularly assembled onto $\mathrm{BiVO}_{4}$, an additional build-in field formed in defective $\mathrm{ZnO}$ nanorods, pushing electrons moving to the bottom of the rods and holes to the lateral sides. At the interfaces between hole-dominated $\{110\}$ of $\mathrm{BiVO}_{4}$ and electron-accumulated $\mathrm{ZnO}$ nanorod ends (right part in Fig. 6c), partial photo-induced holes in $\{110\}$ of $\mathrm{BiVO}_{4}$ and electrons in the ends of $\mathrm{ZnO}$ nanorods may recombine, which was analogous to a $\mathrm{Z}$-scheme mechanism (Fig. S16) [41-43]. The formation of oxygen vacancies further improved the interfacial separation of charge carriers, as evidenced by the significantly prolonged PL lifetime of $\mathrm{Vo}-\mathrm{ZnO} / \mathrm{BiVO}_{4}$ (Fig. S15a). It should be pointed out that the oxygen vacancy-mediated Z-scheme recombination has been recently revealed in the other heterostrctures, suggesting its potential for constructing high-efficiency photocatalysts [44-46]. Meanwhile, the residue holes would migrate to the large lateral surfaces of $\mathrm{ZnO}$ nanorods and thereafter participating in the efficient photooxidation reactions. Similar to those reported in the literatures, small $\{111\}$ facets are occasionally observed in faceted $\mathrm{BiVO}_{4}$ $[8,23,30]$. Theoretical calculations prove the higher CBM and VBM of $\{111\}$ facets than $\{110\}$ facets (Fig. S17). Thus, hole migration from $\{111\}$ facets of $\mathrm{BiVO}_{4}$ to $\mathrm{ZnO}$ is kinetically difficult, i.e. contributed less to the photactivity. As $\{111\}$ facets only take up very low proportion of lateral sides, their impact to the multi-electric field mechanism is neglected here.

The formation of oxygen vacancies could not only enhance the light absorption and electrical conductivity of heterostructures (Fig. S18 and S19a), but also contribute to the interfacial separation of charge carriers. The distribution of oxygen vacancies in the top layer of $\mathrm{ZnO}$ may favorable for the Z-scheme recombination of defect-induced electrons in $\mathrm{ZnO}$ with holes in $\mathrm{BiVO}_{4}$. Accordingly, the internal migration of residual electrons from $\{110\}$ facets of $\mathrm{BiVO}_{4}$ toward $\{010\}$ facets resulted in the efficient separation of charge carriers (Fig. S19b). Both KPFM and TRPL measurements further confirm the charge transfer as indicated in Figure 6c. As a result, the long lived holes accumulated on $\mathrm{ZnO}$ could efficiently oxidize water into $\mathrm{O}_{2}[47,48]$. In contrast, different charge transfer behavior was 
achieved between electron-dominated $\{010\}-\mathrm{BiVO}_{4}$ and $\mathrm{ZnO}$ nanorods (left side in Fig. 6c). Note that oxygen vacancy prefers to form in the top layer of $\mathrm{BiVO}_{4}\{010\}$, it led to the accumulation of electrons on the $\mathrm{BiVO}_{4}\{010\}$ facets, which have a large surface area than $\{110\}$ as indicated in Fig. 3b, thus achieving long lived electrons and holes. On the other hand, we found that without such oxygen vacancies, the photocatalytic activity of $\mathrm{BiVO}_{4} / \mathrm{ZnO}$ is much lower than that with oxygen vacancies (Fig. S20). Therefore, it is believed that the built-in double electric fields, may together with the Z-scheme stepwise accelerate charge transfer in the faceted multi-component architectures.
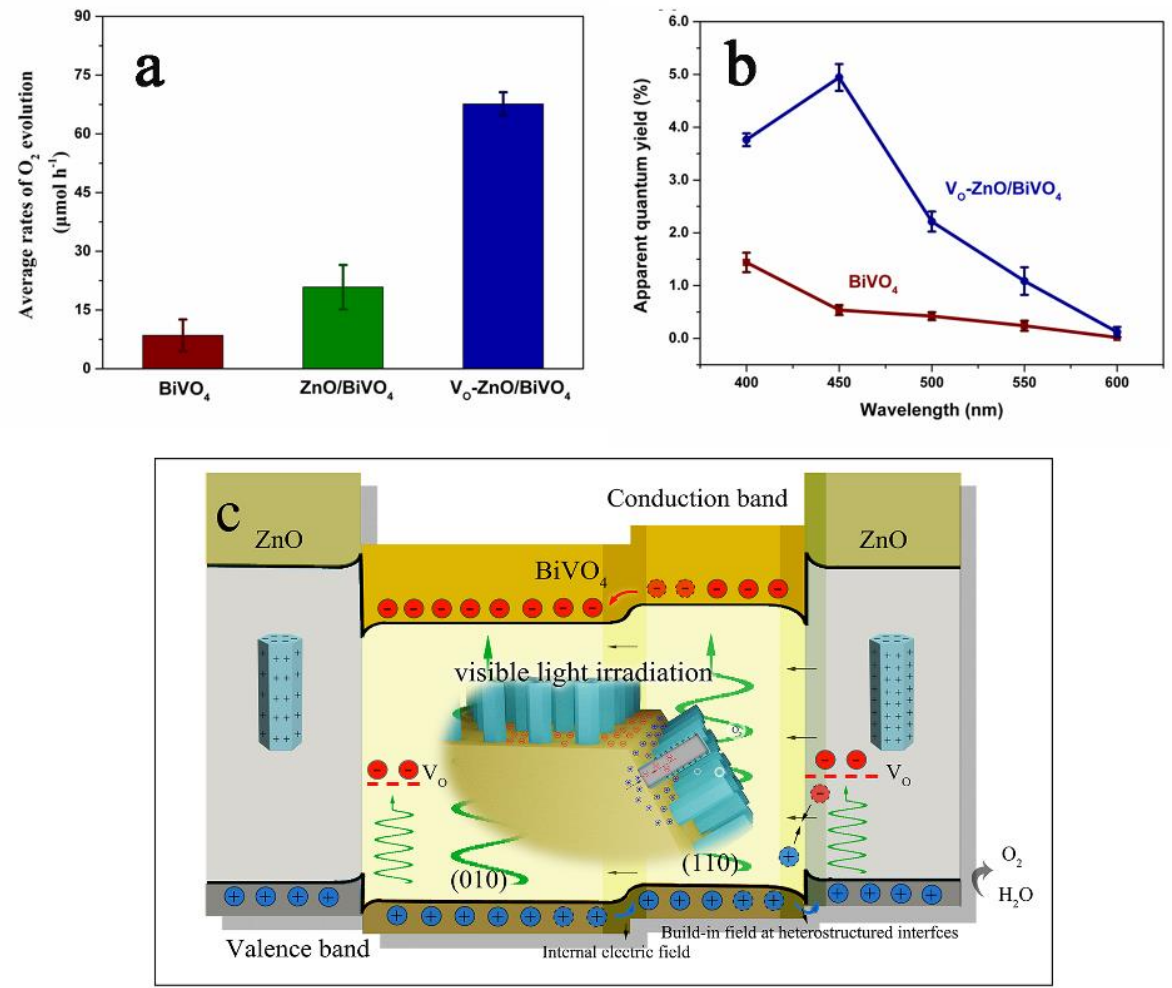

Fig. 6. (a) Photocatalytic water oxidation over $\mathrm{BiVO}_{4}, \mathrm{ZnO} / \mathrm{BiVO}_{4}$ and $\mathrm{V}_{\mathrm{o}}-\mathrm{ZnO} / \mathrm{BiVO}_{4}$ under visible light irradiation $(\lambda>420 \mathrm{~nm})$; (b) Wavelength-dependent $\mathrm{AQY}$ of $\mathrm{BiVO}_{4}$ and $\mathrm{V}_{\mathrm{o}}-\mathrm{ZnO} / \mathrm{BiVO}_{4}$; (c) Schematic representation of double-electric field-assisted charge separation in $\mathrm{ZnO} / \mathrm{BiVO} 4$ heterostructures for water splitting.

To further support the facet-dependent multi-electric field effect, $\mathrm{ZnO}$ nanorods were also coupled with $\mathrm{BiVO}_{4}$ nanosheets with smaller $\{110\}$ facets (denoted as $\mathrm{V}_{\mathrm{o}}-\mathrm{ZnO} / \mathrm{BiVO}_{4}$ nanosheets, Fig. S21). As expected, the smaller surface area of $\mathrm{BiVO}_{4}\{110\}$ facet would lead to less $\mathrm{ZnO}$ nanorods on it, thus efficient charge separation by the double electric field diminish, resulting into similar activity for water oxidation between $\mathrm{BiVO}_{4}$ nanosheets, $\mathrm{ZnO} / \mathrm{BiVO}_{4}$ nanosheets and $\mathrm{Vo}-\mathrm{ZnO} / \mathrm{BiVO}_{4}$ nanosheets (Figure 7b). The impact of crystal facets on the photocatalytic performance of $\mathrm{ZnO} / \mathrm{BiVO}_{4}$ heterostructures was investigated by coupling $\mathrm{ZnO}$ with irregular commercial $\mathrm{BiVO}_{4}$ particles (Fig. S22). This enhanced photocatalytic activity is only observed on the faceted multijunction (Fig. 7d). It further confirms the 
significant contribution of facet-induced electric field to the separation of charge carriers in the heterostructures.
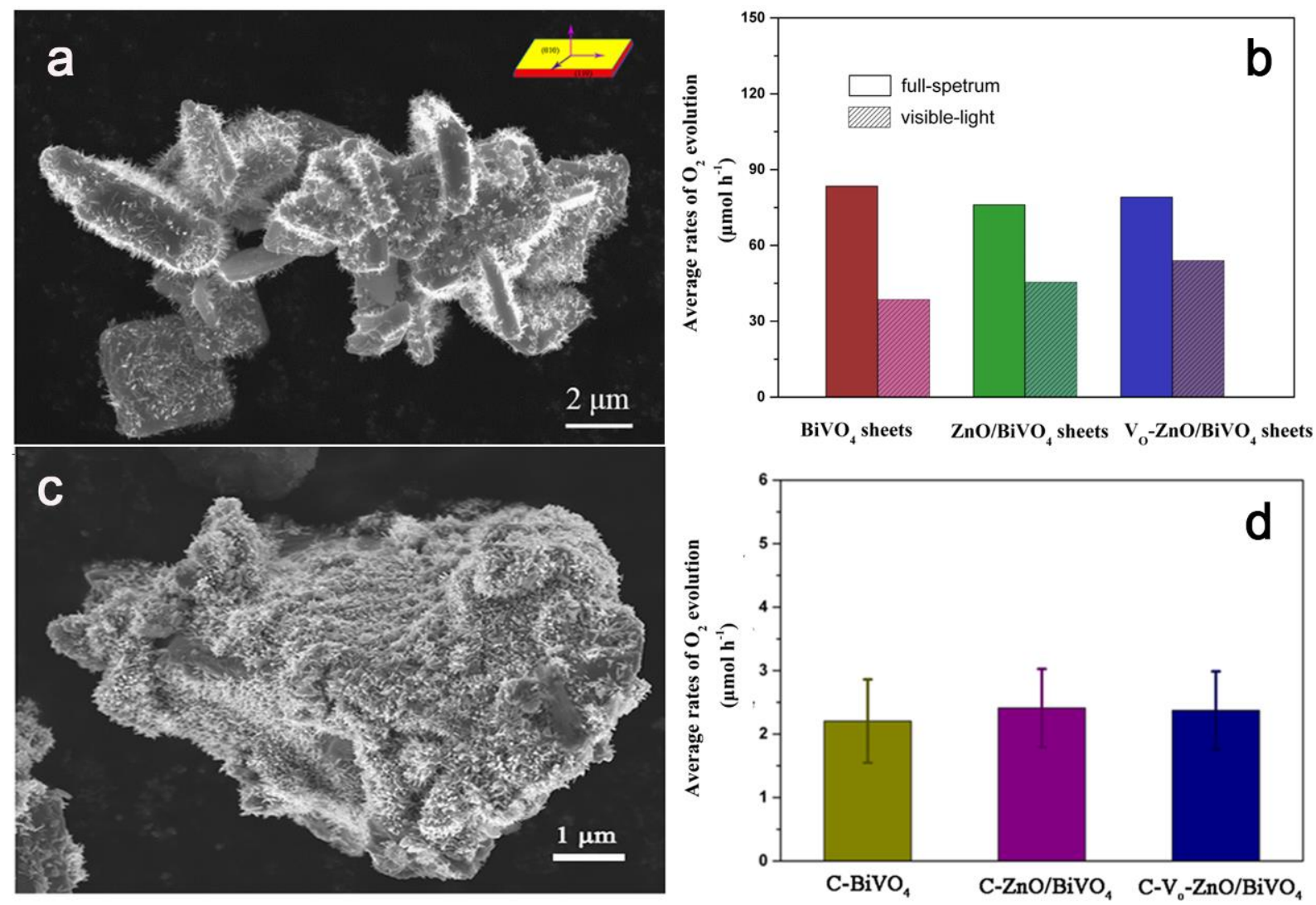

Fig. 7. (a) SEM images of $\mathrm{ZnO} / \mathrm{BiVO}_{4}$ nanosheets; (b) Photocatalytic water oxidation performance of $\mathrm{BiVO}_{4}$ nanosheets, $\mathrm{ZnO} / \mathrm{BiVO}_{4}$ nanosheets and $\mathrm{V}_{\mathrm{o}}-\mathrm{ZnO} / \mathrm{BiVO}_{4}$ nanosheets under full-spectrum and visible-light irradiation. (c) SEM image of $\mathrm{ZnO}$ nanorod/ $\mathrm{BiVO}_{4}$ heterostructures $\left(\mathrm{C}-\mathrm{ZnO} / \mathrm{BiVO}_{4}\right)$; (d) Photocatalytic water oxidation performance of $\mathrm{C}-\mathrm{BiVO}_{4}, \mathrm{C}-\mathrm{ZnO} / \mathrm{BiVO}_{4}$ and $\mathrm{C}-\mathrm{V}_{\mathrm{o}}-\mathrm{ZnO} / \mathrm{BiVO}_{4}$ under visible-light irradiation.

\section{Conclusion}

In summary, $\mathrm{ZnO} / \mathrm{BiVO}_{4}$ hierarchical nanoarchitectures was constructed to demonstrate the strategy of multi-electric field modulation for efficient charge separation. Through the integration of facet engineering with interfacial defect modulation, a remarkable oxygen evolution rate of $68 \mu \mathrm{mol} \bullet \mathrm{h}^{-1}$ was achieved, corresponding to more than one order of magnitude improved AQY (5.0\% at $450 \mathrm{~nm})$ compared with the facted $\mathrm{BiVO}_{4}$ photocatalysts. Both experimental observations and theoretical calculations evidence the facet-dependent photocatalysis mechanism as proved for both high-performance water oxidation and organic decomposition.

\section{Acknowledgments}

This work was supported by the National Natural Science Foundation of China (grant no. 51578531, 51572016 and U1530401). The computation supports from Tianhe-2JK computing time award at the 
Beijing Computational Science Research Center (CSRC) and the Special Program for Applied Research on Super Computation of the NSFC-Guangdong Joint Fund (the second phase) were also acknowledged. This work was also supported by the National Key R\&D Program of China (Grant No. 2016YFC0400500). J. T. acknowledges funding from UK EPSRC grant (EP/N009533/1) and Royal Society-Newton Advanced Fellowship grant (NA150418). The authors thank FT Fan, YY GAO and W Nie for KPFM measurements in Dalian Institute of Chemical Physics, Chinese Academy of Sciences.

Dr. Tingcha Wei and Dr. Yanan Zhu contributed equally to this work.

\section{Supporting information}

Structural characterizations of $\mathrm{ZnO} / \mathrm{BiVO}_{4}$; First-principle simulations; Evaluation of photoactivities of $\mathrm{ZnO} / \mathrm{BiVO}_{4}$ heterostructures; Photocatalytic mechanism of $\mathrm{ZnO} / \mathrm{BiVO}_{4}$ heterostructures; Comparison of the activities of different $\mathrm{BiVO}_{4}$-based photocatalysts.

\section{References:}

[1] M. Shaner, H. Atwater, N. Lewis, E. McFarland, Energy Environ. Sci. 9(2016) 2354-2371.

[2] J. Di, J. Xiong, H. Li, and Z. Liu, Adv. Mater. 30(2018) 1704548.

[3] P. Tran, L. Wong, J. Barber, J. Loo, Energy Environ. Sci. 5(2012) 5902-5918.

[4] L. Mu, Y. Zhao, A. Li, S. Wang, Z. Wang, J. Yang, Y. Wang, T. Liu, R. Chen, J. Zhu, F. Fan, R. Li, C. Li, Energy Environ. Sci. 9(2016) 2463-2469.

[5] D. Martin, G. Liu, S. Moniz, Y. Bi, A. Beale, J. Ye, J. Tang, Chem. Soc. Rev. 44(2015) 7808-7828.

[6] D. Martin, N. Umezawa, X. Chen, J. Ye, J. Tang, Energy Environ. Sci. 6(2013) 3380-3386.

[7] D. Pei, L. Gong, A. Zhang, X. Zhang, J. Chen, Y. Mu, H. Yu, Nature Commun. 6(2015) 8696.

[8] R. Li, H. Han, F. Zhang, D. Wang, C. Li, Energy Environ. Sci. 7(2014) 1369-1376.

[9] S. Moniz, J. Zhu, J. Tang, Adv. Energy Mater. 4(2014) 1301590.

[10] B. Wang, M. Liu, Z. Zhou, L. Guo, Adv. Sci. 2(2015) 1500153.

[11] S. Bai, L. Yang, C. Wang, Y. Lin, J. Lu, J. Jiang, Y. Xiong, Angew. Chem. Int. Ed. 54(2015) 14810-14814.

[12] C. Kim, Y. Son, M. Kang, D. Kim, Y. Kang, Adv. Energy Mater. 5(2015) 1501754;

[13] S. Bai, X. Li, Q. Kong, R. Long, C. Wang, J. Jiang, Y. Xiong, Adv. Mater. 27(2015) 3444-3452.

[14] X. Wu, J. Chen, C. Tan, Y. Zhu, Y. Han, H. Zhang, Nature Chem. 8(2016) 470.

[15] A. Forticaux, S. Hacialioglu, J. DeGrave, R. Dziedzic, S. Jin. ACS Nano. 7(2013) 8224-8232.

[16] C. Campbell, C. Peden, Science 309(2005) 713-714.

[17] X. Chen, L. Liu, P. Yu, S. Mao, Science 331(2011) 746-750.

[18] J. Di, C. Chen, S. Yang, M. Ji, C. Yan, K. Gu, J. Xia, H. Li, S. Li, Z. Liu, J. Mater. Chem. A. 27(2017) 14144-14151. 
[19] J. Di, J. Xia, H. Li, S. Guo, S. Dai, Nano Energy 41(2017) 172-192.

[20] X. An, T. Li, B. Wen, J. Tang, Z. Hu, L. Liu, J. Qu, C. Huang, H. Liu, Adv. Energy Mater. 6(2016) 1502268 .

[21] X. An, L. Zhang, B. Wen, Z. Gu, L. Liu, J. Qu, H. Liu, Nano Energy 35(2017) 290-298.

[22] B. Veal, S. Kim, P. Zapol, H. Iddir, P. Baldo, J. Eastman, Nature Commun. 7(2016) 11892.

[23] J. Zhu, F. Fan, R. Chen, H. An, Z. Feng, C. Li, Angew.Chem. Int. Ed. 54(2015) 9111-9114.

[24] W. Kohn, A. D. Becke, R. G. Parr, J. Phys. Chem. 200(1996) 12974-12980.

[25] G. Kresse, J. Furthmüller, Comp. Mater. Sci. 6(1996) 15-50.

[26] G. Kresse, J. Furthmüller, Phys. Rev. B 54(1996) 11169-11186.

[27] P. E. Blöchl, Phys. Rev. B 50(1994) 17953-17979.

[28] G. Kresse, D. Joubert, Phys. Rev. B 59(1999) 1758-1775.

[29] I. A. Vladimir, F. Aryasetiawan, A. I. Lichtenstein, J. Phys.: Condens. Matter. 9(1997) 767.

[30] R. Li, F. Zhang, D. Wang, J. Yang, M. Li, J. Zhu, X. Zhou, H. Han, C. Li, Nature Commun. 4(2013) 1432.

[31] E. Jang, J. Won, S. Hwang, J. Choy, Adv. Mater. 18(2006) 3309-3312.

[32] F. Schuster, B. Laumer, R. Zamani, C. Magén, J. Morant, J. Arbiol, M. Stutzmann, ACS Nano $8(2014) 4376-4384$.

[33] X. Wang, K. Chen, Y. Zhang, J. Wan, O. L. Warren, J. Oh, J. Li, E. Ma, Z. Shan, Nano Lett. 15(2015) 7886-7892.

[34] C. Pacholski, A. Kornowski and H. Weller, Angew. Chem. 116(2004) 4878-4881.

[35] W. Liu, H. Xu, S. Yan, C. Zhang, L. Wang, C. Wang, L. Yang, X. Wang, L. Zhang, J. Wang, Y. Liu, ACS Appl. Mater. Interfaces 8(2016) 1653-1660.

[36] H. Xu, J. Hu, D. Wang, Z. Li, Q. Zhang, Y. Luo, S. Yu, H. Jiang, J. Am. Chem. Soc. 137(2015) $13440-13443$.

[37] T. Li, J. He, B. PeÇa, C. Berlinguette, Angew. Chem. Int. Ed. 55(2016) 1769-1772 .

[38] G. Dillip, A. Banerjee, V. Anitha, B. Raju, S. Joo, B. Min, ACS Appl. Mater. Inter. 8(2016) 5025-5030.

[39] Y. Zhang, Y. Guo, H. Duan, H. Li, C. Sun, H. Liu, Phys. Chem. Chem. Phys. 16(2014) $24519-24526$.

[40] M. Li, Y. Hu, S. Xie, Y. Huang, Y. Tong, X. Lu, Chem. Commun. 50(2014) 4341-4343.

[41] H. Guo, H. Du, Y. Jiang, N. Jiang, C. Shen, X. Zhou, Y. Liu, A. Xu, J. Phys. Chem. C 121(2017) $107-114$.

[42] J. Ding, Z. Dai, F. Qin, H. Zhao, S. Zhao, R. Chen, Appl. Catal. B-Environ. 205(2017) 281-291.

[43] S. Sultana, S. Mansingh, K. M. Parida, J. Phys. Chem. C 122(2018) 808-819. 
[44] J. Li, M. Zhang, X. Li, Q. Li, J. Yang, Appl. Catal. B-Environ. 212 (2017) 106-114.

[45] J. Ding, Z. Dai, F. Qin, H. Zhao, S. Zhao, R. Chen, Appl. Catal. B-Environ. 205 (2017) 281-291.

[46] Y. Xie, Y. Yang, G. Wang, G. Liu, J. Colloid Interf. Sci. 503 (2017) 198-204.

[47] H. Hussain, G. Tocci, T. Woolcot, X. Torrelles, C. Pang, D. Humphrey, C. Yim, D. Grinter, G.

Cabailh, O. Bikondoa, R. Lindsay, J. Zegenhagen, A. Michaelides, G. Thornton, Nature Mat. 16(2016) 461.

[48] S. Selcuk, A. Selloni, Nature Mater. 15(2016) 1107.

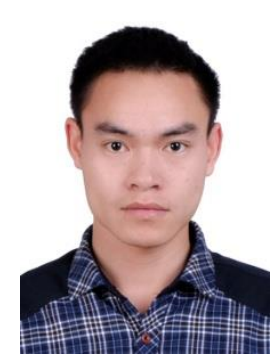

Tingcha Wei received his B.S. in applied physics from Dalian University of Technology in 2013. Now he is a $\mathrm{PhD}$ candidate at Beijing Computational Science Research Center. His research is focused on the defect engineering in metal oxide of photoelectric catalysis.

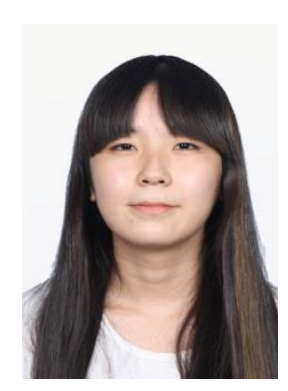

Ya-Nan Zhu received her B.S. in Optical Information Science and Technology from Tongji University in 2015. Now she is a PhD candidate at Beijing Computational Science Research Center. Her research is focused on the first principles calculations on materials of photoelectric catalysis.

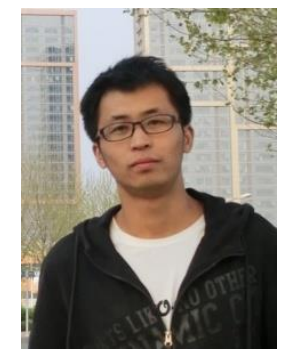

Zhenao Gu is currently a Ph.D. candidate at Research Center for Eco-Environmental Sciences (RCEES), Chinese Academy of Sciences (CAS). His research interests focus on the interfacial design of low-cost metal oxide photocatalysts and photoanodes for efficient solar energy conversion and environmental remediation.

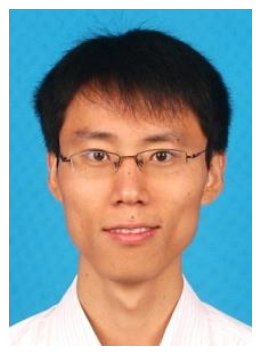

Xiaoqiang An obtained his PhD degree from Beijing Institute of Technology in 2008. In the period of 2011-2013, he conducted his postdoctoral research at the Chinese University of Hong Kong and University College London. After that, he joined in Research Center for Ecological and Environmental Sciences (RCEES), Chinese Academy of Science. Currently, he is an associate professor in Center for Water and Ecology, Tsinghua University. His main research interests focus on solar-driven photocatalytic materials for environmental remediation and renewable energy applications. 


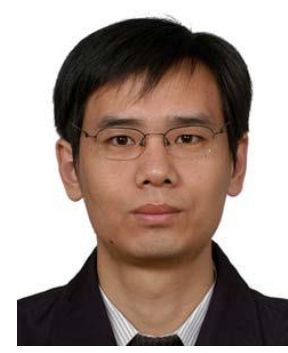

Li-Min Liu received his Ph.D. degree in materials science from the Institute of Metal Research, Chinese Academy of Sciences, in 2006. During his Ph.D. study, he visited Queen's University Belfast for one year. Then he worked at the Fritz Haber Institute, University College London and Princeton University. Since 2012, he works at the Beijing Computational Science Research Center. He has coauthored more than 100 journal papers. He was granted "1000-plan for the young talent" and "the National Science Fund for Excellent Young Scholars". His research interests focus on photocatalysis and aqueous water-solid interfaces for electrocatalysis and fuel cells.

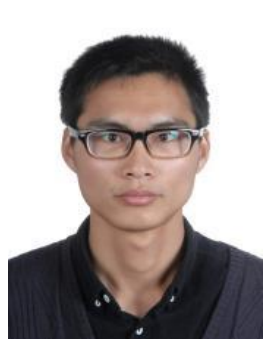

Yu-xuan Wu is a Ph.D. student in Beijing Computational Science Research Center under the supervision of Prof. Li-min Liu. Currently, he is working in Prof. Jiu-hui Qu's group as a visiting scholar at Research Center for Eco-Environmental Science, Chinese Academy of Science. His research interest is synthesis of nanomaterials for photo- and electro-catalytic application.

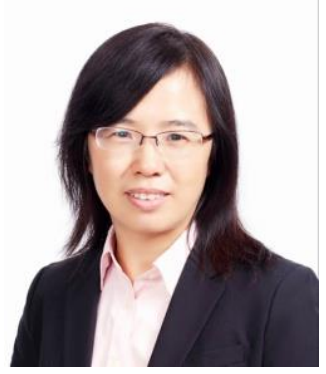

Huijuan Liu received her $\mathrm{PhD}$ degree from the Chinese Academy of Sciences (CAS) in 2003. She is now a full professor of the Center for Water and Ecology, Tsinghua University. She was granted the National Science Fund for Distinguished Young Scholars in 2012. Her research interests focus on the water purifying principle and technology of adsorption, coagulation, photo- and electrochemical processes.

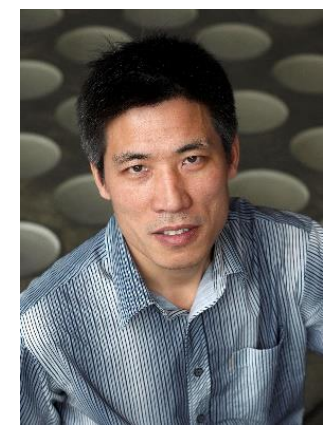

Prof. Junwang Tang is a Fellow of RSC, the Director of UCL Materials Hub and Professor of Chemistry and Materials Engineering in Chemical Engineering at UCL. He received his PhD in Physical Chemistry from DICP, China in 2001. After that, he was appointed as a JSPS Fellow at NIMS, Japan and a senior researcher in Chemistry at Imperial College London, concentrating on photocatalysis and the underlying research mechanism by time-resolved spectroscopies. He then took a faculty position at UCL in 2009. His current research interests lie in photocatalytic small molecule activation ( $\mathrm{CH} 4, \mathrm{~N} 2$ and $\mathrm{H} 2 \mathrm{O})$ and mechanistic aspects of photocatalysis.

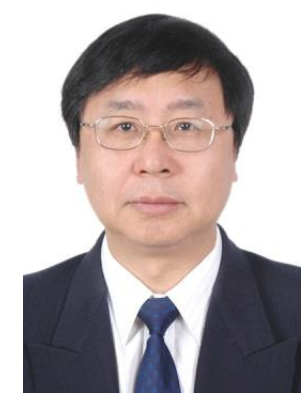

Jiuhui Qu received his PhD degree from Harbin Institute of Technology in 1992, and continued his postdoctoral research there. In 1994, he joined Research Center for Ecological and Environmental Sciences (RCEES), Chinese Academy of Science. He has been an Academician of the Chinese Academy of Engineering since 2009. He serves/served as Vice President of the All-China Environment Federation, Member of the National Environmental Advisory Committee and Board Director of the 
International Water Association (IWA). Dr. Qu's research interests include water pollution control, particularly development of the theories, technologies, and engineering applications relating to drinking water quality and safety. 